\title{
Aspirin, Non-Aspirin Analgesics and the Risk of Hypertension in the SUN Cohort
}

Juan José Beunza, a,b Miguel-Ángel Martínez-González, ${ }^{a}$ Maira Bes-Rastrollo, ${ }^{a}$ Jorge-María Núñez-Córdoba, ${ }^{a}$ Estefanía Toledo, ${ }^{\mathrm{a}, \mathrm{c}}$ and Álvaro Alonso ${ }^{\mathrm{a}, \mathrm{d}}$

aDepartamento de Medicina Preventiva y Salud Pública, Facultad de Medicina, Universidad de Navarra, Clínica Universidad de Navarra, Pamplona, Navarra, Spain

${ }^{b}$ Department of Epidemiology, Harvard School of Public Health, Boston, Massachusetts, USA

'Servicio de Medicina Preventiva, Hospital Virgen del Camino, Pamplona, Navarra, Spain

dDivision of Epidemiology and Community Health, School of Public Health, University of Minnesota,

Minneapolis, Minnesota, USA

Introduction and objectives. The use of aspirin and non-aspirin analgesics have been associated with changes in blood pressure. The aim of this study was to investigate prospectively the association between the regular use of aspirin and non-aspirin analgesics and the incidence of hypertension.

Methods. The SUN project is an ongoing, continuously expanding, prospective cohort of Spanish university graduates initially free of hypertension, cardiovascular disease, diabetes, and cancer; 9986 (mean age, 36 years) were recruited during 1999-2005 and followed up for a mean of 51 months. Regular aspirin and non-aspirin analgesic use and the presence of other risk factors for hypertension were assessed by questionnaire at baseline, and the incidence of hypertension was assessed using biennial follow-up questionnaires.

Results. In total, 543 new cases of hypertension were identified during follow-up. Regular aspirin use (ie, $\geq 2$ days/ week) was associated with a higher risk of hypertension (hazard ratio $=1.45 ; 95 \%$ confidence interval, 1.02-2.04) after adjustment for various confounding factors. Regular use of non-aspirin analgesic drugs was also associated with a higher risk of hypertension (hazard ratio = 1.69; 95\% confidence interval, 1.28-2.23).

Conclusions. The regular use of aspirin and non-aspirin analgesics were both associated with an increased risk

\section{SEE EDITORIAL ON PAGES 265-7}

The Spanish Ministry of Health (Instituto de Salud Carlos III, Fondo de Investigaciones Sanitarias projects PI030678, PI040233, PI042241, PI050514, PI050976, PI070240, PI0801943; RD 06/0045) and the Navarra Regional Government (Department of Health, PI41/2005, PI36/2008).

Correspondence: Dr. J. J. Beunza.

Departamento de Medicina Preventiva y Salud Pública.

Universidad de Navarra.

Irunlarrea, 1, Edificio de Investigación. 31080 Pamplona.

Navarra. Spain.

E-mail: jjbeunza@unav.es

Received February 17, 2009

Accepted for publication October 20, 2009. of developing hypertension, independently of other risk factors.

Key words: Hypertension. Analgesics. Aspirin. SUN project. Cohorts.

\section{Aspirina, analgésicos y riesgo de hipertensión arterial en la Cohorte SUN}

Introducción y objetivos. Se ha relacionado el consumo de aspirina y de otros analgésicos con cambios en la presión arterial. El objetivo de nuestro estudio fue valorar prospectivamente la asociación del uso habitual de aspirina y otros analgésicos con la incidencia de hipertensión arterial.

Métodos. El proyecto SUN es una cohorte prospectiva y dinámica que incluyó a 9.986 graduados universitarios españoles inicialmente libres de hipertensión, enfermedad cardiovascular, diabetes o cáncer (media de edad, 36 años). Fueron reclutados durante el periodo 19992005 y se los siguió prospectivamente durante una media de 51 meses. El uso habitual de aspirina y otros analgésicos, así como la presencia de otros factores de riesgo de hipertensión arterial, se valoró mediante un cuestionario basal. La incidencia de hipertensión se valoró con cuestionarios de seguimiento bienales.

Resultados. Durante el seguimiento se identificaron 543 casos nuevos de hipertensión arterial. El uso habitual de aspirina (2 o más días/semana) se asoció con un mayor riesgo de hipertensión (hazard ratio $[\mathrm{HR}]=1,45$; intervalo de confianza [IC] del 95\%, 1,02-2,04) tras ajustar por diversos factores de confusión. El uso habitual de otros analgésicos diferentes de la aspirina también se asoció a un mayor riesgo de hipertensión arterial $(H R=1,69 ; \mathrm{IC}$ del 95\%, 1,28-2,23).

Conclusiones. El uso habitual tanto de aspirina como de otros analgésicos diferentes a la aspirina parece asociarse a mayor riesgo de hipertensión arterial, independientemente de otros factores de riesgo.

Palabras clave: Hipertensión arterial. Analgésicos. Aspirina. Proyecto SUN. Cohortes. 


\section{ABBREVIATIONS}

BMI: body mass index

BP: blood pressure

$\mathrm{CI}$ : confidence interval

COX: cyclo-oxygenase

HR: hazard ratio

HTN: hypertension

MET: metabolic equivalent

NSAID: non-steroidal anti-inflammatory drug

\section{INTRODUCTION}

Hypertension (HTN) is a major risk factor for cardiovascular disease. ${ }^{1,2}$ Small increases of blood pressure (BP) have relevant and significant effect on morbidity and mortality. ${ }^{3}$ Aspirin and other analgesics like acetaminophen and other non steroidal anti-inflammatory drugs (NSAIDs) are widely used worldwide and could increase the BP levels through prostaglandins inhibition, and through sodium retention in the case of NSAIDs. ${ }^{4}$

Results from different prospective studies conducted in the United States assessing the association between use of aspirin, NSAIDs and other analgesics and the risk of hypertension suggest that chronic users of aspirin, NSAIDS, and acetaminophen have a higher risk of hypertension. ${ }^{5-9}$ However, some clinical trials conducted in Spain have shown the opposite effect ${ }^{10,11}$ and no previous prospective study has assessed this potential relationship in a European cohort, where a different health system probably means different access to medication and a different pattern of drug use. ${ }^{12}$

Our objective was to assess the association between regular use of aspirin and non-aspirin analgesic drugs and the incidence of HTN in a prospective dynamic cohort study consisting of Spanish university graduates, the SUN (Seguimiento Universidad de Navarra, University of Navarra Follow-up) project.

\section{METHODS}

The SUN project is a dynamic cohort of university graduates in Spain. The objectives and methods of the SUN cohort have been reported with detail elsewhere. ${ }^{13,14}$ Briefly, beginning in December 1999 a letter of invitation and a mailed questionnaire was sent to all alumni of the University of Navarra and other university graduates living in Spain. The baseline questionnaire gathered information on sociodemographic variables, lifestyle, including diet and physical activity, and medical information. Because of the dynamic cohort design, enrollment of participants is continuously open. The study protocol has been approved by the Institutional Review Board of the University of Navarra. The response to the initial questionnaire was considered as an informed consent to participate in the study.

Follow-up of the SUN participants is made through biennial mailed questionnaires collecting information about changes in lifestyles and risk factors, and presence of medical conditions. Up to 5 mailings are sent to non-respondents. In January 2008, the SUN cohort included 18922 participants who had answered the baseline questionnaire. For this analysis we considered 15222 individuals who answered the baseline questionnaire before January 22, 2005 and had the chance to complete at least the first follow-up questionnaire. A total of 13563 participants had answered one of the follow up questionnaires (retention rate, $89 \%$ ). From these, we excluded 1503 participants qualified as prevalent cases of HTN (defined as a self-reported medical diagnosis of HTN, use of antihypertensive medication, selfreported systolic BP $>140 \mathrm{~mm} \mathrm{Hg}$ or diastolic BP $>90 \mathrm{~mm} \mathrm{Hg}$ in the baseline questionnaire), and 1273 as prevalent cases of cardiovascular disease, diabetes, or cancer. In addition, 1214 had extreme caloric intake (total energy intake $>4200 \mathrm{kcal} / \mathrm{d}$ or $<800 \mathrm{kcal} / \mathrm{d}$ for men, or $>3500 \mathrm{kcal} / \mathrm{d}$ or $<500$ $\mathrm{kcal} / \mathrm{d}$ for women) and 272 had missing information in any of the covariates used in the analysis. After applying the previous criteria, we excluded a total of 3577 participants. Thus, 9986 participants were considered for analyses.

\section{Assessment of Exposure}

At baseline, participants were asked whether they usually took aspirin at least 2 days a week and whether they usually took analgesic drugs other than aspirin.

\section{Assessment of Incident Hypertension}

In the follow-up questionnaires participants were asked whether they had received a medical diagnosis of HTN in the time after they completed the previous questionnaire. The date (month and year) of the diagnosis was also requested. Incident cases of HTN were defined as those individuals selfreporting a medical diagnosis of HTN in any of the follow-up questionnaires who did not have HTN at baseline. We have observed an acceptable validity of the self-reported diagnosis of HTN among our highly educated cohort, comparing it with objective 
measurements of BP in a random subsample of the cohort. ${ }^{15,16}$

\section{Assessment of Covariates}

The baseline questionnaire requested additional information about a wide array of sociodemographic factors (sex, age, university degree, marital and employment status), anthropometric measurements (weight, height), health-related habits (diet, smoking status, alcohol consumption, and physical activity), and clinical variables (use of medication, personal and family history of hypertension, hypercholesterolemia, coronary heart disease, cancer, and other diseases). We calculated the body mass index (BMI) using the self-reported weight in kilograms divided by the square of height in meters. The amount of physical activity during leisure time was quantified from an activity metabolic equivalent (MET) index, computed by assigning a multiple of resting metabolic rate (MET score) to each of 17 activities included in the baseline questionnaire. ${ }^{17}$ Time spent in each of the activities was multiplied by the MET score specific to each activity. Then, the value of overall weekly MET-hours activity was obtained from the sum of all activities. The validity of self reported weight and leisure-time physical activity has been demonstrated in the SUN cohort. ${ }^{18,19}$ Dietary habits were assessed using a semiquantitative food-frequency questionnaire with 136 items, previously validated in Spain. ${ }^{20}$

\section{Statistical Analysis}

We estimated hazard ratios (HR) and their 95\% confidence interval (CI) for the risk of incident hypertension according to the regular use of aspirin and non-aspirin analgesic drugs using a multivariable Cox regression analysis. Time of follow-up was defined as the time elapsed from the completion of the baseline questionnaire to the diagnosis of HTN or the date of the last follow-up questionnaire, whichever came earlier. We ran age (continuous) and sex-adjusted models and an additional model adjusting for the following variables: sex (binary), age (continuous), baseline BMI (continuous), leisure-time physical activity (total METs as continuous), alcohol intake (continuous), family history of hypertension (binary), self-reported hypercholesterolemia (binary), smoking (current and past smokers vs never smokers), energy adjusted sodium intake, olive oil, fruit, vegetable, and lowfat dairy consumption (all of them in quartiles). Some of these variables were selected as well known risk factors for hypertension; others were selected because they have shown to be associated with hypertension in previous studies done in this same population. The model containing all these variables will be subsequently referred to as the multivariable Cox regression model. To test for the existence of confounding by indication, we conducted an additional analysis adjusting for a diagnosis of rheumatoid arthritis, gastric ulcer or headache at baseline.

We repeated the analyses after stratifying by gender, age and BMI in order to assess potential effect modification (interaction) by these variables, and formally tested the interactions introducing product-terms in the multivariable Cox regression models.

\section{RESULTS}

At baseline, the mean age of the 9986 participants included in the analyses was 36 years. During the follow-up period (mean, 51 months), we observed 543 incident cases of hypertension. The distribution of potential confounding variables according to aspirin and non-aspirin analgesic use is displayed in Table 1. Regular use of aspirin was associated with being male, older, smoker, having a higher BMI, not engaging in leisure-time physical activities, drinking more alcohol, and presenting higher intake of sodium, fruits, and vegetables. Regular use of non-aspirin analgesic drugs was associated with being female, not engaging in leisure-time physical activities, taking less alcohol, more vegetables and low-fat dairy, and having more family history of hypertension.

Aspirin regular use was significantly associated with incident hypertension $(\mathrm{HR}=1.45 ; 95 \% \mathrm{CI}$, 1.02-2.04) after adjustment for multiple potential confounders (Table 2). Use of non-aspirin analgesic drugs (other analgesic drugs) was also associated with incident hypertension both before and after adjustment for multiple potential confounders (HR $=1.69 ; 95 \%$ CI, 1.28-2.23) (Table 2). We repeated the analyses including simultaneously aspirin and other analgesic drugs use in the model. Results did not appreciably change and are displayed in Table 2. Finally, Table 3 reports analyses stratified by sex. Association estimates had wider confidence intervals. Results were similar for people younger or older than 34.5 years (median), younger and older than 45 years, and for normoweight and overweight participants (data not shown). Results were also similar when adjusting for total energy intake and for consumption of the following items, first as continuous and then as quintiles: red meat, total fat, mono-unsaturated fat, poli-unsaturated fat, and saturated fat (results not shown).

There was no evidence of any potential statistical interaction. Specifically, interaction terms for age and aspirin or other analgesic drugs use were $P=.16$ 
TABLE 1. Distribution of Potential Confounding Variables According to Baseline Regular Aspirin and Non-Aspirin Analgesic Use in the SUN Study, 1999-2005

\begin{tabular}{|c|c|c|c|c|}
\hline & \multicolumn{2}{|c|}{ Aspirin } & \multicolumn{2}{|c|}{ Non-Aspirin Analgesic Drugs } \\
\hline & Yes & No & Yes & No \\
\hline Participants, $\mathrm{n}$ & 333 & 9653 & 798 & 9188 \\
\hline Male, \% & 45.9 & 38.3 & 22.3 & 40 \\
\hline Age, mean, y & 41.26 & 36.18 & 35.31 & 36.44 \\
\hline $\mathrm{BMl}$, mean, kg/m2 & 23.8 & 23.1 & 23 & 23.1 \\
\hline Physical activity, mean, METS-h/wk & 22.4 & 24.5 & 21.3 & 24.7 \\
\hline Smoker, \% ${ }^{a}$ & 64 & 50 & 54 & 50 \\
\hline Alcohol intake, mean, $\mathrm{g} / \mathrm{d}$ & 8 & 6 & 5 & 6 \\
\hline Family history of hypertension, $\%$ & 37 & 38 & 41 & 38 \\
\hline Sodium intake, mean, $\mathrm{g} / \mathrm{d}$ & 4.4 & 4 & 4.3 & 4 \\
\hline Hypercholesterolemia, self-reported, \% & 14 & 14 & 14 & 14 \\
\hline Fruits intake, mean, $\mathrm{g} / \mathrm{d}$ & 367 & 329 & 337 & 329 \\
\hline Vegetables intake, mean, $\mathrm{g} / \mathrm{d}$ & 556 & 504 & 542 & 503 \\
\hline Olive oil intake, mean, $\mathrm{g} / \mathrm{d}$ & 17 & 18 & 19 & 18 \\
\hline Low-fat dairy intake, mean, $\mathrm{g} / \mathrm{d}$ & 207 & 215 & 268 & 210 \\
\hline
\end{tabular}

BMl indicates body mass index; MET, metabolic equivalent.

${ }^{\mathrm{a} C u r r e n t}$ and past smokers.

TABLE 2. HR (95\% Cl) of Self-Reported Hypertension According to Baseline Regular Aspirin and Non-Aspirin Analgesic Drugs Regular Use in the SUN Study, 1999-2005

\begin{tabular}{|c|c|c|c|}
\hline & No & Yes & Total \\
\hline \multicolumn{4}{|l|}{ Aspirin } \\
\hline New cases of HTN, $n$ & 507 & 36 & 543 \\
\hline Person-years, $\mathrm{n}$ & 40529 & 1404 & 41933 \\
\hline Age and sex adjusted, HR (95\% Cl) & 1 (Ref) & $1.35(0.96-1.90)$ & \\
\hline Multivariate 1, HRa $(95 \% \mathrm{Cl})$ & 1 (Ref) & $1.45(1.03-2.05)$ & \\
\hline Multivariate $2, \mathrm{HRb}(95 \% \mathrm{Cl})$ & 1 (Ref) & $1.42(1.00-2.00)$ & \\
\hline \multicolumn{4}{|l|}{ Non-aspirin analgesis use } \\
\hline New cases of HTN, $n$ & 486 & 57 & 543 \\
\hline Person-years, $n$ & 38679 & 3255 & 41933 \\
\hline Age and sex adjusted, HR (95\% Cl) & 1 (Ref) & $1.58(1.21-2.05)$ & \\
\hline Multivariate $1, \mathrm{HRa}(95 \% \mathrm{Cl})$ & 1 (Ref) & $1.69(1.28-2.23)$ & \\
\hline Multivariate 2, HRc (95\% IC) & 1 (Ref) & $1.67(1.26-2.21)$ & \\
\hline
\end{tabular}

$\mathrm{Cl}$ indicates confidence interval; HR, hazard ratio; HTN, hypertension.

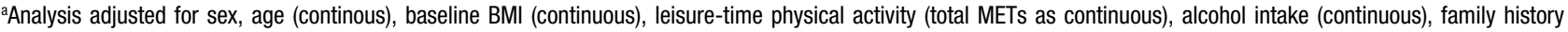
of hypertension (binary), self-reported hypercholesterolemia (binary), smoking (current and past smokers vs never smokers), energy adjusted sodium (quartiles), olive oil (quartiles), fruit (quartiles), vegetable (quartiles), and low-fat dairy consumption (quartiles).

'Same as multivariate 1 plus adjustment for non-aspirin analgesic drugs use.

'Same as multivariate 1 plus adjustment for aspirin use.

and $P=.97$ respectively, for BMI were $P=.76$ and $P=.59$ respectively, and finally for gender were $P=.63$ and $P=.30$ respectively.

A total of 47 participants took both aspirin and other analgesic drugs. Results did not change significantly after excluding them $(\mathrm{HR}=1.45 ; 95 \%$ CI, 1.02-2.04 for aspirin and $\mathrm{HR}=1.69 ; 95 \% \mathrm{CI}$, 1.28-2.23 for other analgesic drugs). In addition, we created a new variable including 4 categories (non-users, aspirin users, other analgesic drugs users, and both aspirin and other analgesic drugs users). Participants who took both aspirin and other analgesic drugs presented a $\mathrm{HR}=2.31(95 \% \mathrm{CI}$,
0.95-5.61) when compared to non-users. Finally, to control for potential confounding by indication, we repeated the analyses including the baseline diagnosis of rheumatoid arthritis, gastric ulcers, and headache, observing similar results (data not shown).

\section{DISCUSSION}

In this analysis of the SUN project, we have observed that regular use of both aspirin and nonaspirin analgesic drugs could be associated with a higher risk of incident HTN independently of other risk factors. 
TABLE 3. HR (95\% CI) of Self-Reported Hypertension According to Intake of Aspirin and Non-Aspirin Analgesic Drugs Regular Intake Stratified by Sex, the SUN Study, 1999-2005

\begin{tabular}{|c|c|c|c|}
\hline & No & Yes & Total \\
\hline \multicolumn{4}{|l|}{ Men } \\
\hline \multicolumn{4}{|l|}{ Aspirin } \\
\hline New cases of HTN, $n$ & 323 & 25 & 348 \\
\hline Person-years, $\mathrm{n}$ & 15150 & 644 & 15794 \\
\hline Age adjusted, HR (95\% Cl) & 1 (Ref) & $1.29(0.85-1.95)$ & \\
\hline Multivariate, HRa (95\% IC) & 1 (Ref) & $1.42(0.94-2.16)$ & \\
\hline \multicolumn{4}{|l|}{ Non-aspirin analgesics drugs } \\
\hline New cases of HTN, $n$ & 316 & 32 & 348 \\
\hline Person-years, $n$ & 15077 & 717 & 15794 \\
\hline Age adjusted, HR (95\% Cl) & 1 (Ref) & $1.84(1.30-2.61)$ & \\
\hline Multivariate, HRa (95\% IC) & 1 (Ref) & $1.96(1.36-2.84)$ & \\
\hline \multicolumn{4}{|l|}{ Women } \\
\hline \multicolumn{4}{|l|}{ Aspirin } \\
\hline New cases of HTN, $n$ & 184 & 11 & 195 \\
\hline Person-years, $n$ & 25380 & 760 & 26139 \\
\hline Age adjusted, HR (95\% Cl) & 1 (Ref) & $1.58(0.86-2.92)$ & \\
\hline Multivariate, $\mathrm{HRa}(95 \% \mathrm{IC})$ & 1 (Ref) & $1.41(0.76-2.62)$ & \\
\hline \multicolumn{4}{|l|}{ Non-aspirin analgesics drugs } \\
\hline New cases of HTN, $n$ & 170 & 25 & 195 \\
\hline Person-years, $\mathrm{n}$ & 23602 & 2538 & 26139 \\
\hline Age and sex adjusted, HR (95\% Cl) & 1 (Ref) & $1.32(0.88-1.99)$ & \\
\hline Multivariate, $\mathrm{HRa}(95 \%$ IC) & 1 (Ref) & $1.39(0.91-2.12)$ & \\
\hline
\end{tabular}

Cl indicates confidence interval; HR, hazard ratio; HTN, hypertension.

aAnalysis adjusted for age (continous), baseline BMI (continuous), leisure-time physical activity (total METs as continuous), alcohol intake (continuous), family history of hypertension (binary), self-reported hypercholesterolemia (binary), smoking (current and past smokers versus never smokers), energy adjusted sodium (quartiles), olive oil (quartiles), fruit (quartiles), vegetable (quartiles), and low-fat dairy consumption (quartiles).

Previous prospective epidemiological studies have assessed the association between aspirin, acetaminophen, or NSAID use and incident hypertension. Analyses from the Nurses' Health Study(NSH)comparing thehighest(>22days/month) with the lowest (none) exposure group found that increased frequency of use of aspirin, acetaminophen, or NSAIDs, was associated with an increased risk of self reported physician-diagnosed HTN (aspirin, $\mathrm{RR}=1.21 ; 95 \% \mathrm{CI}, 1.13-1.30$; acetaminophen, RR $=1.20 ; 95 \%$ CI, $1.08-1.33$; NSAIDs, RR $=1.35 ; 95 \%$ CI, 1.25-1.46). ${ }^{6}$ A later analysis of the NHS II found similar results for acetaminophen $(\mathrm{RR}=2 ; 95 \% \mathrm{CI}$, $1.52-2.62)$ and for NSAIDs ( $\mathrm{RR}=1.86 ; 95 \% \mathrm{CI}$, $1.51-2.28$ ), but no significant association was found for aspirin. ${ }^{5}$ However, the mean age in this second analysis was lower (range, 31-50) than in the first one (range, 49-61). Finally, other analyses including selected participants from both the NHS and NHS II together did not find a global association for aspirin $(\mathrm{RR}=1.12 ; 95 \% \mathrm{CI}, 0.67-1.86$ among older women and $\mathrm{RR}=1.35 ; 95 \% \mathrm{CI}, 0.84-2.18$ among younger women) but they detected a marginal association only among younger women ( $P$ for trend .06). ${ }^{8}$ Results from cumulative analgesic use for 14 years in the Physicians' Health Study did not find significant results for any of the drugs (aspirin,
$\mathrm{RR}=1.16 ; 95 \%$ CI, 0.92-1.48; acetaminophen, $\mathrm{RR}$ $=1.08 ; 95 \%$ CI, $0.87-1.58 ;$ NSAIDs, $\mathrm{RR}=1.05 ; 95 \%$ CI, 0.89-1.24). ${ }^{9}$ However, 96\% of the participants were habitual aspirin users (daily $235 \mathrm{mg}$ of aspirin) and this homogeneous distribution of the assessed exposure may have reduced the power of the study to detect a small to moderately elevated risk of HTN due to aspirin intake. ${ }^{9}$ Finally, analyses from the Health Professionals Follow-up Study assessed the association between NSAID consumption (6-7 days per week vs none) and self-reported hypertension. ${ }^{7}$ They found an adjusted RR $=1.26(95 \% \mathrm{CI}, 1.14-$ $1.40 ; P<.001$ for trend) for aspirin, $\mathrm{RR}=1.34(95 \%$ CI, 1.00-1.79; $P<.01$ for trend) for acetaminophen, and $\mathrm{RR}=1.38(95 \% \mathrm{CI}, 1.09-1.75 ; P<.002$ for trend $)$ for NSAIDs. ${ }^{7}$

Some trials have also assessed the association between analgesic use and BP changes. In relation to the use of aspirin, the Hypertension Optimal Treatment Study (HOT) analyzed 18790 hypertensive patients in an age range of 50 to 80 years, with mean follow up 3.8 years. They compared aspirin ( $75 \mathrm{mg} /$ day) versus placebo. $\mathrm{BP}$ in the aspirin group was $0.6 / 0.3 \mathrm{~mm} \mathrm{Hg}$ higher than in the control group, suggesting a positive association. However, these BP changes were clinically irrelevant when compared to the BP changes attributed to the anti- 
hypertensive therapy. ${ }^{21}$ Some other cross-over trials have assessed whether aspirin may counteract the effect of anti-hypertensive drugs on BP. So far, no interaction has been found, though the number of patients involved in these studies was very small (less than 19 patients). ${ }^{22,23}$ On the other hand, Hermida et al reported an inverse association between aspirin intake ( $100 \mathrm{mg} /$ day) given before bed-time and mean 24 hour BP levels (-6/-4 mm Hg reduction of systolic $\mathrm{BP} /$ diastolic BP ${ }^{10}$ especially in non-dippers. ${ }^{11}$ They attributed this difference in the circadian variations to factors mediating BP control, mainly plasma renin activity, angiotensin II and catecholamines. In this sense, another trial reported a reduction of 24-h ambulatory BP monitoring (systolic BP, -5.7 [2.6] $\mathrm{mm} \mathrm{Hg} ; P=.008 ; \mathrm{DBP},-3.8$ [1.7] mm Hg; $P=.014$ ) in hypertensive patients with hypercholesterolemia taking antihypertensive medication, statins and aspirin (intervention group) compared to antihypertensive medication and statins alone (control group). ${ }^{24}$

Two meta-analyses assessing the association of aspirin and other NSAIDs with BP levels have been published. The first meta-analysis found that among a total of 771 participants, NSAIDs increased mean blood pressure by $5 \mathrm{~mm} \mathrm{Hg}$ overall $(95 \% \mathrm{CI}$, 1.28.7). ${ }^{25}$ However, the effect was largely limited to hypertensive participants receiving antihypertensive therapy. Regarding aspirin treatment, they included 8 trials with a total of 105 hypertensive individuals taking $\geq 1.5 \mathrm{~g}$ daily, and found no significant association..$^{25}$ The second meta-analysis found a $3 \mathrm{~mm} \mathrm{Hg}$ increase in mean blood pressure with NSAIDs that was also limited to participants with preexisting hypertension. ${ }^{26}$ In addition, among the different NSAIDs, only indomethacin and naproxen were associated with increased blood pressure, while ibuprofen and sulindac, were not. Regarding specifically aspirin, the meta-analysis included 14 normotensive and 39 hypertensive individuals taking also $\geq 1.5 \mathrm{~g}$ daily, finding an increase of mean BP of $0.61 \mathrm{~mm} \mathrm{Hg}$ before adjusting for salt intake, and a reduction of $1.62 \mathrm{~mm} \mathrm{Hg}$ in the normotensive group and $1.76 \mathrm{~mm} \mathrm{Hg}$ in the hypertensive group, after adjustment for salt intake. The main limitation of both meta-analyses is the reduced number of studies and subjects included.

Several mechanisms could explain the observed association between aspirin or NSAIDs and incident HTN. The most widely proposed and accepted mechanism is blockage of cyclooxygenase (COX) enzymes. ${ }^{4,27} \mathrm{COX}-1$ is related to normal cell function, like protective gastric mucosa secretion in the stomach, salt and water handling in the kidney or platelet and endothelium normal function. COX2 is more related to inflammatory states, manifested with pain, heat, and swelling. COX-1 inhibition is responsible for one of the most important NSAIDs side-effects: gastritis. COX-2 inhibition reduces prostaglandin synthesis and is related to the antiinflammatory, analgesic, and antipyretic effects of aspirin and other non-selective NSAIDs. COX2 inhibition may also be the pathway through which aspirin may increase the BP levels. First, through prostacyclin (PGI2) reduction that increases in turn systemic vascular resistance due to unopposed vasoconstriction of angiotensin II and catecholamines, and that also increases renal vascular resistance with reduced natriuresis and sodium and water retention., ${ }^{4,27}$ Second, through prostaglandin E2 reduction which may reduce natriuresis by $30 \%$ $50 \%$, especially in patients with chronic kidney disease (a potential conditions in individuals taking COX inhibitors chronically). ${ }^{28-31}$ Finally, some authors propose inhibition of aldosterone metabolism with subsequent hyperaldosteronism, as a potential mechanism for increased BP in aspirin users. ${ }^{32} \mathrm{On}$ the other hand, acetaminophen blocks the COX enzyme at its peroxidase rather than cyclooxygenase catalytic site, and therefore it has different tissue specificity and less anti-inflammatory and platelet function inhibitory effect. ${ }^{33}$

There are some limitations in our study. First of all, the small number of events might lead to unstable models. Secondly, our outcome is selfreported. Abundant evidence, however, indicates that self-reported information about HTN diagnosis is valid for epidemiological studies, ${ }^{34}$ particularly among highly educated participants. ${ }^{35}$ Given the high educational level of our participants and the universal health care access in the Spanish population, we can assume a high validity of selfreported HTN diagnosis. Finally, considering medical diagnosis of HTN as the outcome instead of using single BP measurements decreases the chances of finding false positives. In fact, in a validation study conducted in a randomly selected subsample of our cohort, we observed acceptable positive and negative predictive values for self-reported medical diagnoses of hypertension, even when our gold standard, which was a repeated direct measurement, missed true cases of hypertension..$^{15}$ Nevertheless, some degree of information bias is likely to exist. This could be an important problem if those who take aspirin or non-aspirin analgesic drugs more often, receive closer medical attention, since it would be easier for them to be diagnosed as hypertensives in comparison to those who do not take these drugs. We acknowledge the possibility of this bias, given that our estimates for the HR were not very large. Thirdly, residual or unmeasured confounding could explain the observed association. Those who do not take aspirin and non-aspirin analgesic drugs may have an overall healthier lifestyle. However, 
although we cannot rule out the existence of unmeasured confounders, we adjusted our analysis for the most important known risk factors for hypertension and other lifestyle variables such as smoking, which could act as markers of general lifestyle. Additional analyses including possible indications, or contraindications, for NSAID use did not greatly impact our estimates. Even after adjusting for other analgesics (non-aspirin analgesics in the analysis of aspirin, and aspirin in the analysis of non-aspirin analgesics) the association remained. Although we validated most of the information in the questionnaires, ${ }^{18-20}$ sodium intake is not easily measured with food-frequency questionnaires and could partially explain the observed association. An added limitation is therefore the lack of sodium measurement through 24 hours urine collection. Finally, we also face the limited information on the exposure, since more detailed information on drug dosage and type of drug, etc, would have been useful especially in relation to a possible dose-effect gradient.

\section{CONCLUSIONS}

In conclusion, regular use of aspirin or other non-aspirin analgesic drugs could be associated with incident HTN in a Spanish group of university graduates. Further studies are warranted.

\section{ACKNOWLEDGMENTS}

We are indebted to the participants of the SUN project for their continued cooperation and participation. We also thank others members of the SUN study group including: M Segui-Gomez, J de Irala, JA Martinez, A Marti, M Serrano-Martinez, F Guillen-Grima, $C$ de la Fuente-Arrillaga, JF Basterra-Gortari, Z Vazquez, S Benito, A Tortosa, University of Navarra; M Delgado-Rodriguez, University of Jaen; J Llorca, University of Cantabria; E Smyth, University of Santiago de Compostela; A Sanchez-Villegas, University of Las Palmas; I Marques-Lopes, University of Saragossa; and CN Lopez, Harvard University. We thank the members of the Department of Nutrition of the Harvard School of Public Health (A Ascherio, FB $\mathrm{Hu}$, WC Willett) who helped us to design the SUN project. We also thank Prof Santidrian for sharing his wisdom with all of us, and La Caixa Foundation for their support to the main author.

\section{REFERENCES}

1. Lawes CM, Vander Hoorn S, Rodgers A. Global burden of blood-pressure-related disease, 2001. Lancet. 2008;371:1513-8.
2. Cushman WC. The burden of uncontrolled hypertension: morbidity and mortality associated with disease progression. $\mathbf{J}$ Clin Hypertens (Greenwich). 2003;5:14-22.

3. MacMahon S, Peto R, Cutler J, Collins R, Sorlie P, Neaton J, Abbott R, Godwin J, Dyer A, Stamler J. Blood pressure, stroke, and coronary heart disease. Part 1. Prolonged differences in blood pressure: prospective observational studies corrected for the regression dilution bias. Lancet. 1990;335:765-74.

4. Murray MD, Lazaridis EN, Brizendine E, Haag K, Becker P, Brater DC. The effect of nonsteroidal anti-inflammatory drugs on electrolyte homeostasis and blood pressure in young and elderly persons with and without renal insufficiency. Am $\mathbf{J}$ Med Sci. 1997;314:80-8.

5. Curhan GC, Willett WC, Rosner B, Stampfer MJ. Frequency of analgesic use and risk of hypertension in younger women. Arch Intern Med. 2002;162:2204-8.

6. Dedier J, Stampfer MJ, Hankinson SE, Willett WC, Speizer FE, Curhan GC. Nonnarcotic analgesic use and the risk of hypertension in US women. Hypertension. 2002;40:604-8.

7. Forman JP, Rimm EB, Curhan GC. Frequency of analgesic use and risk of hypertension among men. Arch Intern Med. 2007;167:394-9.

8. Forman JP, Stampfer MJ, Curhan GC. Non-narcotic analgesic dose and risk of incident hypertension in US women. Hypertension. 2005;46:500-7.

9. Kurth T, Hennekens CH, Sturmer T, Sesso HD, Glynn RJ, Buring JE, et al. Analgesic use and risk of subsequent hypertension in apparently healthy men. Arch Intern Med. 2005;165:1903-9.

10. Hermida RC, Ayala DE, Calvo C, Lopez JE, Fernandez JR, Mojon A, et al. Administration time-dependent effects of aspirin on blood pressure in untreated hypertensive patients. Hypertension. 2003;41:1259-67.

11. Hermida RC, Ayala DE, Calvo C, Ayala DE, Calvo C, Lopez JE, et al. Differing administration time-dependent effects of aspirin on blood pressure in dipper and non-dipper hypertensives. Hypertension. 2005;46:1060-8.

12. Hanoch Y, Katsikopoulos KV, Gummerum M, Brass EP. American and German students' knowledge, perceptions, and behaviors with respect to over-the-counter pain relievers. Health Psychol. 2007;26:802-6.

13. Seguí-Gómez M, de la Fuente C, Vazquez Z, de Irala J, Martínez-González MA. Cohort profile: the 'Seguimiento Universidad de Navarra' (SUN) study. Int J Epidemiol. 2006;35:1417-22.

14. Martínez-González MA, Sánchez-Villegas A, De IJ, Martí A, Martínez JA. Mediterranean diet and stroke: objectives and design of the SUN project. Seguimiento Universidad de Navarra. Nutr Neurosci. 2002,5:65-73.

15. Alonso A, Beunza JJ, Delgado-Rodríguez M, MartínezGonzález MA. Validation of self reported diagnosis of hypertension in a cohort of university graduates in Spain. BMC Public Health. 2005;5:94.

16. Beunza JJ, Martínez-González MA, Serrano-Martínez M, Alonso A. Incidence of hypertension in a cohort of Spanish university graduates: the SUN study. Rev Esp Cardiol. 2006;59:1331-4.

17. Ainsworth BE, Haskell WL, Whitt MC, Irwin ML, Swartz AM, Strath SJ, et al. Compendium of physical activities: an update of activity codes and MET intensities. Med Sci Sports Exerc. 2000;32:S498-S504.

18. Bes-Rastrollo M. Validation of self-reported weight and body mass index in the participants of a cohort of university graduates. Rev Esp Obes. 2006;3:183-9.

19. Martínez-González MA, López-Fontana C, Varo JJ, SanchezVillegas A, Martínez JA. Validation of the Spanish version of the physical activity questionnaire used in the Nurses' Health Study and the Health Professionals' Follow-up Study. Public Health Nutr. 2005;8:920-7. 
20. Martín-Moreno JM, Boyle P, Gorgojo L, Maisonneuve P, Fernández-Rodríguez JC, Salvini S, Willett WC. Development and validation of a food frequency questionnaire in Spain. Int J Epidemiol. 1993 ;22:512-9.

21. Zanchetti A, Hansson L, Leonetti G, Rahn KH, Ruilope L, Warnold I, Wedel H. Low-dose aspirin does not interfere with the blood pressure-lowering effects of antihypertensive therapy. J Hypertens. 2002;20:1015-22.

22. Polonia J, Boaventura I, Gama G, Camoes I, Bernardo F, Andrade $\mathrm{P}$, et al. Influence of non-steroidal anti-inflammatory drugs on renal function and $24 \mathrm{~h}$ ambulatory blood pressurereducing effects of enalapril and nifedipine gastrointestinal therapeutic system in hypertensive patients. J Hypertens. 1995;13:925-31.

23. Nawarskas JJ, Townsend RR, Cirigliano MD, Spinler SA. Effect of aspirin on blood pressure in hypertensive patients taking enalapril or losartan. Am J Hypertens. 1999;12:784-9.

24. Magen E, Viskoper JR, Mishal J, Priluk R, London D, Yosefy C. Effects of low-dose aspirin on blood pressure and endothelial function of treated hypertensive hypercholesterolaemic subjects. J Hum Hypertens. 2005;19:667-73.

25. Johnson AG, Nguyen TV, Day RO. Do nonsteroidal antiinflammatory drugs affect blood pressure? A meta-analysis. Ann Intern Med. 1994;121:289-300.

26 Pope JE, Anderson JJ. A meta-analysis of the effects of nonsteroideal anti-inflammatory drugs on blood pressure. Arch Intern Med. 1993;153:477-84.

27. Mulkerrin EC, Clark BA, Epstein FH. Increased salt retention and hypertension from non-steroidal agents in the elderly. QJM. 1997;90:411-5.
28. Brater DC. Effects of nonsteroidal anti-inflammatory drugs on renal function: focus on cyclooxygenase-2-selective inhibition. Am J Med. 1999;107:65S-70S.

29. Qi Z, Hao CM, Langenbach RI, Breyer RM, Redha R, Morrow JD, et al. Opposite effects of cyclooxygenase-1 and -2 activity on the pressor response to angiotensin II. J Clin Invest. 2002;110:61-9.

30. Whelton A. Nephrotoxicity of nonsteroidal anti-inflammatory drugs: physiologic foundations and clinical implications. Am J Med. 1999; 106:13S-24S.

31. Whelton A, Schulman G, Wallemark C, Drower EJ, Isakson PC, Verburg KM, et al. Effects of celecoxib and naproxen on renal function in the elderly. Arch Intern Med. 2000;160:1465-70.

32. Knights KM, Mangoni AA, Miners JO. Non-selective nonsteroidal anti-inflammatory drugs and cardiovascular events: is aldosterone the silent partner in crime? Br J Clin Pharmacol. 2006;61:738-40.

33. Aronoff DM, Oates JA, Boutaud O. New insights into the mechanism of action of acetaminophen: Its clinical pharmacologic characteristics reflect its inhibition of the two prostaglandin $\mathrm{H} 2$ synthases. Clin Pharmacol Ther. 2006;79:9-19.

34. Tormo MJ, Navarro C, Chirlaque MD, Barber X. Validation of self diagnosis of high blood pressure in a sample of the Spanish EPIC cohort: overall agreement and predictive values. EPIC Group of Spain. J Epidemiol Community Health. 2000;54:2216.

35. Colditz GA, Martin P, Stampfer MJ, Willett WC, Sampson $\mathrm{L}$, Rosner B, et al. Validation of questionnaire information on risk factors and disease outcomes in a prospective cohort study of women. Am J Epidemiol. 1986;123:894-900. 